\title{
Investigating the effect of the centralized planning system on developing the critical thinking in junior school students
}

\author{
Rezgar Mohammadi ${ }^{1, *}$, Ezatullah Naderi ${ }^{2}$ \\ ${ }^{1}$ Member of the Faculty Staff at the Islamic Azad University, Saghez Branch, \\ Islamic Azad University, Saghez, Iran \\ ${ }^{2}$ Associate professor, Science and Research Branch Tehran, Islamic Azad University, Tehran, Iran \\ *E-mail address: mohammadi.rezgar@yahoo.com
}

\begin{abstract}
The aim of the present research is to investigate the effect of the centralized planning system on developing the critical thinking among junior school students. This research is an applied one. The statistical population of this research includes third grade junior school students of the Kurdistan province ( 9372 girls and 11521 boys). The selected sample in this research, in accordance with the nature of the research population and its characteristics that was selected through the multi stage cluster and classified sampling includes 220 junior school students. The Watson and Glaser critical thinking questionnaire was used for measuring the critical thinking and for analyzing the data; the $\mathrm{Z}$ test and Levine test were used. Results indicated that the centralized planning system will decrease critical thinking among junior school students. The centralized planning system will reduce the inference ability, deduction ability, interpretation ability, and the evaluative ability of logical arguments while it increases the ability to identify assumptions among junior school students.
\end{abstract}

Keywords: Curriculum planning; Centralized system; Decentralized system, Teacher; Critical thinking

\section{INTRODUCTION}

Since years ago, the Iranian organizational and administrative system has been a centralized system and the government has itself assumed responsibility of most of the affair. After the victory of the Islamic revolution, with the implementation of the third and fourth development plan, effective measures to reduce centralization, specifically in the economic areas were adopted. In line with these policies, over the recent years, the ministry of education has adopted a series of measures to reform the organizational structure, increasing the powers of the general education offices to the organization's powers level at the provincial level. Despite an increase in the financial and management powers of the provinces, unfortunately nationwide curricula are still designed and implemented quite centrally in the country. Studies performed and available evidence in the curricula of the Iranian high school and general educational courses suggest a centralized designing system and the production of the equal curricula for all the students (Salsabili, 2007). These curricula are often times contentcentered, and heavily rely on the unified textbook. Personal, social, regional, and environmental differences are not dealt with and the content takes the notified, formal prescriptive and universal form. However, in the non-centralized systems, the central 
governments cede the powers to the lower rank institutional units. Of course, to establish coordination the central government intervenes in implementing the plans and oversees them.

A lack of centralization includes: a transfer of a part or all of the decision making processes and the responsibilities of the centralized governments to local and regional governments (counties, institutions, municipalities or schools themselves). Local and regional governments could change curricular priorities of teaching methods and educational management, by considering budgets and costs or adapt themselves to them (UNESCO, 2005). Using a single textbook is a feature of curriculum centered educational system. Given the fact that the Iranian educational system is currently curriculum centered and the education at schools is based on a single textbook, non-textbooks are produced and published; while in countries where the educational systems are student centered and different sources are applied for the education task, all the related books with the education curricula are regarded as nontextbooks and the concept of textbook is senseless (Seid Ghotbi, 2010).

In the end, it should be mentioned that a successful implementation of the national curricula with any degree of reduced centralization, requires a reconstruction of the educational system and fundamental changes. An expectation of an effective participation of the regions, schools and teachers in implementing the national curricula is contingent on a precise determination of the scope of powers, establishment of required professional skills and systematic support within the implementation of the national curricula to the institutionalization phase of the plan.

Thoughtful and intellectual designers should in the area of organizing and shaping the educational classes and environments as well as training teachers and outlining clear and important directions in the education arena make fundamental changes; this of course, needs the coordination of the educational body; outside, the education ministry can't do much. The success of the students in the today's society is based on taking into account a critical thinking, and formulating appropriate curricula in relation with it. We need to develop a critical morale among learners in order that they can create for themselves analysis ability, sound judgment and a right insight into the evaluation and criticizing values, and different cultures and meantime retain their own cultural independence, and as a result accept or reject a critical thinking of the affair.

Hence, schools should develop the critical thinking in such a way that they can expand their own logical and argumentative abilities (Hashemyan Nezhad, 2002). John Dewey, (1982), defines the nature of the critical thinking as the absolute judgment that includes an exact investigation of the beliefs, experiences, knowledge and information followed by judgment (Khalili, 2000). Brookfield agrees that feeling are important for the critical thinking because when a person attempts to think critically and to help others to do it, must be aware of the importance of his feelings for this activity (Sismon, p. 929, 2002).

In his M.A. thesis, Alipour (2006) has investigated the relationship of the content of books social teachings with developing critical thinking skills. In this research the content analysis method was used, but due to the limited population, sampling was not made. Results indicate that the content of such books develop none of the critical thinking skills (analysis, combination, evaluation, judgment and summing up). Ferdowsi (1994), in part of his own research on the factors related to the content of lessons, leading to the inattention of the students to lesson contents concluded that from the viewpoint of the students, the lessons content being abstract, the unspecified necessity and application of the lessons, lack of coordination of the lesson content with the goals and needs of the students as well as a huge volume and a variety of the concepts expressed in different lessons have ranked first to fourth on the inattention list of the students to the lessons content. This issue clearly shows the problems that exist in the selection and the organization of the book contents. The findings of this research indicate for the students to pay more attention to lessons, it is imperative that 
lesson content volume and their concepts be reduced and be formulated in accordance with the today's needs if the students. The needs, necessity and the application of each lesson should be organized and presented appropriately.

In case the content of the lessons is adjusted well, making the students think critically and analytically towards the presented content, it will render in developing a divergent and creative thinking. Malaki and Habibpour (2006), concluded that great scholars, placing an emphasis on the importance of thinking, believes that developing thinking is one of the main goals of the education process. On this ground, the educational system should instead of transferring the mere information to the students, provide appropriate situations for developing thinking among the children. Given the fact that the educational system of Iran is centralized and the educational programs are already designed and formulated, in this research the role of the curricular planning process of Iran on developing the thinking skills is dealt with and reasons are cited for that. The current research attempts to answer the following hypothesis: The centralized educational system influences the development of the critical thinking among the junior school students.

\section{METHODOLOGY}

The aim of the present research is to investigate the effect of the centralized planning system on developing the critical thinking among junior school students. This research is an applied one. The statistical population of this research includes third grade junior school students of the Kurdistan province (9372 girls and 11521 boys). The selected sample in this research, in accordance with the nature of the research population and its characteristics that was selected through the multi stage cluster and classified sampling includes 220 junior school students. The Watson and Glaser critical thinking questionnaire was used for measuring the critical thinking and for analyzing the data; the $\mathrm{Z}$ test and Levine test were used. As said to collect data the Watson and Glaser critical thinking questionnaire measures the critical thinking through 80 questions in five factors of the inference, identifying assumptions, deduction, interpretation and evaluation skills.

The total score of the test is 80 and the highest score of each participant for each section is 16. Scores in the inference section are obtained by way of accuracy and inaccuracy of the phrases, in the identifying assumption section, they are obtained through determining the existence of presumptions or lack of them thereto, in the mentioned or unmentioned phrases of the situations. In the deduction section, scores are acquired through specifying attained or unattained results of the situations while scores in the interpretation section are achieved through interpretations of the results of the events and lastly, in the evaluation section, scores are obtained by way of determining strong and weak reasons. In other words, in this test, for each correct answer, a score is given to the person and the total of the correct responses to the test questions is called the total score (maximum of 80 scores). Each of the subjects based on the acquired total score, could be placed in one of the classes (less than 54), average (54-59) and strong (60-80) from a perspective of critical thinking ability.

In dividing the scores of each section, the lower class, average and the strong class are considered as 10 and lesser, 11 and 12-16 respectively. The time needed to answer the questions of the test is 60 minutes. This test, after being edited and translated to Farsi was investigated in order to coordinate and adapt it with the social and cultural factors of Iran. In the process of the standardization of the test of Glaser-Watson critical thinking skills, the reliability coefficient by different researches in Iran based in the Cronbach's alpha test was reported as over 0/70 (Mosalla Nezhad, 2009; Eslami Akbar et al, 2005). 


\section{FINDINGS}

Table1. Results of the one sample $\mathrm{z}$ test for the significance of ten critical thinking of the junior school students.

\begin{tabular}{|c|l|l|c|c|c|c|}
\hline Indices/variables & No. & Z score & $\begin{array}{c}\text { Under } \\
\text { normal } \\
\text { curve } \\
\text { level }\end{array}$ & $\begin{array}{c}\text { Hypothetical } \\
\text { average of the } \\
\text { population }\end{array}$ & Average & Significance \\
\hline $\begin{array}{c}\text { Junior school } \\
\text { students' critical } \\
\text { thinking }\end{array}$ & 220 & $16 / 47$ & $0 / 5000$ & 23 & 16 & $0 / 001$ \\
\hline
\end{tabular}

As seen in the Table 1, the $\mathrm{z}$ obtained for the critical thinking of the students is 16/47 which is significant at the $0 / 01$ level with the significance level of $0 / 001(p \leq 0 / 01)$. As a result the null hypothesis, indicating a lack of difference of the averages is rejected. Hence, according to the average of the subjects (16), and comparing it with the hypothetical average of the population (23), it can be concluded that the obtained average is significantly lower than the hypothetical average of the population and the twelfth hypothesis at the 0/01 level is significant at an inverse direction. Therefore, it can be said that the centralized educational system has a negative impact on developing the critical thinking of the junior school students. In other words, the system causes the critical thinking of the students to decline.

Table 2. Result of the one sample $\mathrm{z}$ test for the significance of the factors of the critical thinking among junior school students.

\begin{tabular}{|c|l|l|c|c|c|c|}
\hline Indices/variables & No. & Z score & $\begin{array}{c}\text { Under } \\
\text { normal } \\
\text { curve } \\
\text { level }\end{array}$ & $\begin{array}{c}\text { Hypothetic } \\
\text { al average } \\
\text { of the } \\
\text { population }\end{array}$ & Average & Significance \\
\hline Inference ability & 220 & $22 / 18$ & $0 / 5000$ & 5 & $3 / 077$ & $0 / 000$ \\
\hline $\begin{array}{c}\text { Identifying } \\
\text { assumptions }\end{array}$ & 220 & $2 / 26$ & $0 / 4881$ & 5 & $5 / 3818$ & $0 / 01$ \\
\hline $\begin{array}{c}\text { Deduction ability } \\
\begin{array}{c}\text { Interpretation } \\
\text { ability }\end{array}\end{array}$ & 220 & $18 / 18$ & $0 / 5000$ & 5 & $3 / 4409$ & $0 / 000$ \\
\hline $\begin{array}{c}\text { Evaluative ability } \\
\text { of logical } \\
\text { arguments }\end{array}$ & 220 & $10 / 07$ & $0 / 5000$ & 5 & $3 / 4409$ & $0 / 000$ \\
\hline
\end{tabular}


As seen in the Table 2, the $\mathrm{z}$ acquired for the inference ability is $22 / 18$ which is significant at the $0 / 01$ level with the significance level of $0 / 000(p \leq 0 / 01)$. In other words, the centralized educational system reduces the inference ability among the junior school students. Also the $z$ acquired for the identifying assumptions among students is $2 / 26$ which is significant at the $0 / 01$ level with the significance level of $0 / 000(p \leq 0 / 01)$. In other words, the system increases this ability among the junior school students.

Also the $\mathrm{z}$ acquired for the deduction ability was 19/6 which is significant at the $0 / 01$ level with the significance level of $0 / 000(p \leq 0 / 01)$. In other words, the centralized educational system reduces the deduction ability among the students. Also the $\mathrm{z}$ acquired for the interpretation ability was $18 / 18$ which is significant at the $0 / 01$ level with the significance level of $0 / 000(p \leq 0 / 01)$. Hence, the system decreases this ability among the students . Also the $\mathrm{z}$ acquired for the evaluative ability of the logical arguments of the students is $10 / 07$ which is significant at the $0 / 01$ level with the significance level of $0 / 000(p \leq 0 / 01)$. In other words, the system reduces this ability among the students .

Table 3. Levine test to hypothesize the establishment of variances in the factors of the critical thinking in the two groups.

\begin{tabular}{|c|c|c|c|c|}
\hline Variables & $\mathrm{F}$ & $\begin{array}{c}\text { Freedom } \\
\text { degrees 1 }\end{array}$ & $\begin{array}{c}\text { Freedom } \\
\text { degrees 2 }\end{array}$ & Significant level \\
\hline Analysis & $0 / 15$ & 1 & 218 & $0 / 69$ \\
\hline Evaluation & $0 / 02$ & 1 & 218 & $0 / 96$ \\
\hline Deduction & $2 / 25$ & 1 & 218 & $0 / 13$ \\
\hline Syllogism & $0 / 77$ & 1 & 218 & $0 / 38$ \\
\hline Induction & $0 / 01$ & & & $0 / 91$ \\
\hline
\end{tabular}

As seen in the Table 3 of the Levine test the value of the statistic $\mathrm{F}$ is not significant in all the variables, indicating that the variance of all the groups in all the critical factors are equal.

Table 4. Table of confirming the multivariate variance analysis of the groups.

\begin{tabular}{|c|c|c|c|c|}
\hline Trace & Value & F & $\begin{array}{c}\text { Freedom } \\
\text { degrees }\end{array}$ & $\begin{array}{c}\text { Significance } \\
\text { level }\end{array}$ \\
\hline Pillai's trace & $0 / 02$ & $0 / 97$ & 5 & $0 / 43$ \\
\hline Lambd a Wilcks & $0 / 97$ & $0 / 97$ & 5 & $0 / 43$ \\
\hline Hotelling trace & $0 / 02$ & $0 / 97$ & 5 & $0 / 43$ \\
\hline $\begin{array}{c}\text { Largest Roy's } \\
\text { root }\end{array}$ & $0 / 02$ & $0 / 97$ & & $0 / 43$ \\
\hline
\end{tabular}


As seen the value of Lambd a Wilcks is $0 / 95$ which is not significant, indicating that there is not a significant difference in the critical thinking.

Table 5. Multivariate variance analysis between girls and boys with regards to critical thinking.

\begin{tabular}{|c|c|c|c|c|c|c|}
\hline Source & Scales & $\begin{array}{c}\text { Squared } \\
\text { sum }\end{array}$ & $\begin{array}{c}\text { Freedom } \\
\text { degrees }\end{array}$ & $\begin{array}{c}\text { Squared } \\
\text { average }\end{array}$ & F & $\begin{array}{c}\text { Significance } \\
\text { level }\end{array}$ \\
\hline \multirow{5}{*}{ Groups } & Analysis & $1 / 16$ & 1 & $1 / 16$ & $0 / 68$ & $0 / 40$ \\
\cline { 2 - 7 } & Evaluation & $0 / 01$ & 1 & $0 / 01$ & $0 / 008$ & $0 / 92$ \\
\cline { 2 - 7 } & Deduction & $1 / 31$ & 1 & $1 / 31$ & $0 / 91$ & $0 / 34$ \\
\cline { 2 - 7 } & Syllogism & $5 / 56$ & 1 & $5 / 56$ & $3 / 48$ & $0 / 06$ \\
\cline { 2 - 7 } & Induction & $0 / 04$ & & $0 / 04$ & $0 / 01$ & $0 / 89$ \\
\hline
\end{tabular}

As seen in Table. 4. The hypothesis "The centralized educational system influences the development of the critical thinking among the junior school students" ( $p \leq 0 / 05)$ is not supported. This means that with regards to critical thinking factors there is no meaningful difference between girls and boys.

\section{DISCUSSION}

Results indicate that the centralized educational system has a negative impact on the junior school students. Also, he results indicated that the system will decrease critical thinking among junior school students. The centralized planning system will reduce the inference ability, deduction ability, interpretation ability, and the evaluative ability of logical arguments while it increases the ability to identify assumptions among junior school students.

In recent years, educational experts have expressed concerns over the inability of the learners in terms of the critical thinking. While developing thinking skills of the learners has also been a complex issue within the educational areas, it is now a critical issue. It is due to the fact that the output of the social information has exceeded the peoples' critical thinking abilities about this information.

Today the amount of the information at hand, is beyond the ability of the people to use it and hence, in such conditions, education centers as the reservoir of the information and teachers as the lecturers and transferors of the information should change and the learners should increase their own skills in thinking and arguments, instead of a sheer acquiring and remembering the information. They should also try to process the available information and apply it (Ebili, 2002). In accordance with the conducted researches, as much as $50 \%$ of the learnt content is forgotten after one year while $80 \%$ of them are forgotten after two years. This research recommends conditions with regards to minimizing the forgetfulness level that one of them is the opportunity to apply them in daily life. 
In other words, what is learnt, if applied in daily life, is forgotten to a lesser extent compared to the thing having no application (forgetfulness limits less than $15 \%$ ). Therefore, once the concentration of goals on the specialized information is obtainable and its results are permanent when possibility of its application in daily life is more. Learning is effective when learners could discuss the learnable. Since, expanding the teaching styles requires a type of interaction among the counterparts and a type of feedback, this learnable material could be obtained very well. Lectures and presenting teaching material should be minimized and students should be get engaged in other strategies frequently through repeated questions. However the ability to think critically depends on the teaching style and educational patterns in use as well as the way a person studies and therefore, the at the time of teaching and studying like a critic, the critical thinking occurs at the wake of facing issues and situations (Shabani and Mehrmohammadi, 2001). The results of the research correspond with those of the following researches: Pasyar and Esteghamat (2010) investigated the questions related to the critical thinking of the book Biology of the third year of high school. For this, they applied the skills by Peter Fascione that include interpretation, analysis, evaluation, inference, explanation and self-regulation in order that the minimum of the skills considered in each of the questions were to be measured. Results revealed that the explanation skill was totally taken into account and the inference, evaluation, interpretation and analysis skills were respectively expected by the designers in designing the questions.

The least of attention was directed at the last and the most important thinking skill of self-assessment. Alipour (2010), in a research titled the obstacles to the critical thinking in the high school curricula (placing an emphasis on analysis, combination, evaluation and judgment skills) showed that the quantitative research results indicate that developing a critical thinking in the high school years face obstacles like lack of attention to the analysis skill, combination skill, evaluation and judgment skills as well as then summing up skill where this lack of attention is observed in the elements of the high school curricula like purpose, content, teaching style and evaluation.

In his M.A. thesis, Alipour, (2006) has investigated the relationship of the content of books social teachings with developing critical thinking skills. In this research the content analysis method was used, but due to the limited population, sampling was not made. Results indicate that the content of such books develop none of the critical thinking skills (analysis, combination, evaluation, judgment and summing up). Ferdowsi, (1994), in part of his own research on the factors related to the content of lessons, leading to the inattention of the students to lesson contents concluded that from the viewpoint of the students, the lessons content being abstract, the unspecified necessity and application of the lessons, lack of coordination of the lesson content with the goals and needs of the students as well as a huge volume and a variety of the concepts expressed in different lessons have ranked first to fourth on the inattention list of the students to the lessons content. This issue clearly shows the problems that exist in the selection and the organization of the book contents. The findings of this research indicate for the students to pay more attention to lessons, it is imperative that lesson content volume and their concepts be reduced and be formulated in accordance with the today's needs if the students. The needs, necessity and the application of each lesson should be organized and presented appropriately. In case the content of the lessons is adjusted well, making the students think critically and analytically towards the presented content, it will render in developing a divergent and creative thinking. Malaki and Habibpour (2006) concluded that a great scholar, placing an emphasis on the importance of thinking, believes that developing thinking is one of the main goals of the education process.

On this ground, the educational system should instead of transferring the mere information to the students, provide appropriate situations for developing thinking among the children. Given the fact that the educational system of Iran is centralized and the educational 
programs are already designed and formulated, in this research the role of the curricular planning process of Iran on developing the thinking skills is dealt with and reasons are cited for that. The current research attempts to answer the following hypothesis: The centralized educational system influences the development of the critical thinking among the junior school students.

\section{RECOMMENDATIONS - CONCLUSIONS}

- Researches should be performed on the thinking poverty among students as a result of the governing traditional methods in the Iranian schools at different educational levels and guidelines are presented to remove this problem.

- Establishing fundamental changes in educating the human workforce, specifically teachers in line with enhancing the planning ability as well as teaching and considering their role in the curriculum planning.

- Adopting a problem orientation approach in designing educational and curricular programs, changing the main course of the curriculum from transferring knowledge to exploring accordance with scientific methods.

\section{References}

[1] Alipour, V. (2005). Investigating the content of the junior school books from a viewpoint of the critical thinking, M.A. thesis of the Tarbyat Modarres University.

[2] Ebili, Kh. (2002). Education of the critical thinking, Third volume, Tehran: SAMT publications.

[3] Eslamiakbar, R., Behbahani, N., Rouh Angiez, J. (2005). A comparison of the critical thinking of the nursing students of the first and last semesters majoring in clinical nursing, Iran nurses, 15-19.

[4] Ferdowsi, T. (1994). Investigating the effective factors in the inattention of the students to the contents of the book, Talim and Tarbyat Periodical, 21-41.

[5] Hashemyan Nezad, F. (2002). Developing the critical thinking-papers of the conference of the curriculum and developing thought.

[6] Khalili, H. (2000). Validity and the norm of the scores of the California critical thinking test (form B). M.A thesis, Faculty of nursing and obstetrician of the medical sciences, University of Shahid Beheshti.

[7] Mosalla Nezhad, L. (2009). An investigation of the traditional and virtual critical thinking of computer, Journal of Educational and Medical Studies.

[8] Salsabili, N. (2008). The transition of the Iranian curricular system towards a decentralization in designing and formulating the curricula by emphasizing on the school based curriculum planning, 4: 49-68.

[9] Seid Ghotbi, S M. (2002). The role and position of the textbook and non-textbook as well as institute libraries in the Iranian educational system and in the world, a Review on the Texts, 10-11, 12- 20. 
[10] Shabani, H., Mehrmohammadi, M. (2001). Developing the critical thinking using the problem oriented education, Modarres publication No.1.

[11] Simpson, E. (2002). Critical Thinking in Nursing Education. The Journal Of Nursing Practice, 8(2), 89-98.

[12] UNESCO counseling group. (2005). The process of the educational planning, trans: By Faride Mashayekh, Tehran: Madrase publication. 